the chloroform is so permeable that the air can find no diffculty in traversing it, nor the respiration suffer any restraintcircumstances not existing to the same degree under the use of other measures adopted or proposed."-p.9.

The Journal of Psychological Medicine, \&c., for April, 1850. THE present number not only well maintains its reputation as a source of interest and instruction to those specially engaged in the treatment of insanity, but can be recommended, like many of its quarterly forerunners, as capable of affording, in the shape of an hour's after-dinner desultory reading, much that will interest the practitioner of general medicine relative to the lighter literature of many departments of intellectual philosophy, viewed in its more physiologic and medical aspects. This combination of two kinds of information renders Dr. Winslow's journal worthy of very extensive patronage, for the student of a highly important specialite will meet with that which is worthy of his most attentive study, and the fatigued practititioner may enjoy an evening's excursion in a field of medical literature which will be one both of pleasure and of profit. To all students who are "getting up the train" we strongly advise a perusal of Mr. Coote's paper. The first lecture of Dr. Hitchman leads us to infer that his contributions which are to follow will be of no mean value and importance. The present number contains a short but curious autobiography-if we may so call it-of one who really believes he is possessed by a devil.

$\longrightarrow$

\section{A fitíror}

\section{OF THE PRACTICE OF}

\section{MEDICINE AND SURGERY IN THE} \section{HOSPITALS OF LONDON.}

\author{
St. Thomas's HospitaI. \\ Dry Gangrene of Foot. - Death: Autopsy. \\ (Under the care of Mr. Le Gros Clark.)
}

W lately observed a very instructive case of dry gangrene among the patients of Mr. Le Gros Clark, and availing ourselves of Mr. Chaldecott's notes, we proceed to place the details of the same before our readers.

The patient, thirty-eight years of age, and a pork-butcher by trade, had been accustomed to drink immoderately of spirits, and was much emaciated when admitted on the 9th of February, 1850. He stated that three weeks before admission he was seized with rigors while cleaning a horse, and lost the use of his legs; they both felt numbed, and he experienced a tingling sensation in them. Patient had to be carried home; he was subsequently attacked with erratic pains in the joints, and two days before admission, the left foot began to turn black, and the pain in the joints diminished. The foot, when first seen, was of a dark bluish, black colour, as far as the tarso-metatarsal articulation, where a distinct line of demarcation had formed, and was beginning to ulcerate. At the lower and inner part of the foot, the mortification extended farther, and the line of demarcation was less apparent. The rest of the limb presented a normal appearance; the artery could not be felt pulsating in the ham, and but very feebly, if at all, in the groin. The patient was weak, slept badly; his countenance was anxious; the pulse 90 , feeble, and the tongue red, especially at the tip and edges. The first sound of the heart was prolonged, but there was no bruit.

Mr. Clark ordered ammonia and bitter tonics, after the primo vioe had been cleared; a poultice was applied to the foot, and two ounces of brandy, and six ounces of wine, with good diet, were allowed. The patient, however, passed very bad, restless nights, with occasional delirium, and though well supported and plentifully supplied with stimulants, he became gradually much enfeebled, nervous, and irritable, complaining at times of much pain in the foot. The process of separation was, however, noticed to be going on slowly, but healthily. No amendment occurred in the foregoing symptoms, and about seventeen days after admission, vomiting supervened, perspiration appeared in large drops in the patient's forehead, he grew gradually weaker, and though stimulants were not spared, he died about twenty days after entering the hospital, whilst, with the aid of another patient, he was turning in bed.

The post-mortem examination was conducted by Mr. William Adams, demonstrator of morbid anatomy to the hospital. The foot was found in a condition of soft gangrene as far as the middle of the instep, and in a line extending backwards to the heel; a distinct line of demarcation, extending partly through the soft parts, was apparent. The left lung was extremely congested, and œdematous throughout; on section, thick pus oozed abtundantly from the divided bronchial tubes; the right lung was pretty well in the same condition as the left, but not so congested. Nothing very remarkable was found in the heart, save a fibrinous clot of an irregular cylindrical form, which was firmly and inseparably adherent to the linirg membrane of the left auricle, about half an inch above the attached border of the mitral valve. The clot passed through the auriculo-ventricular opening, and continuous with it was a mass of recent colourless fibrine contained in the left ventricle. This mass of fibrine, though continuous from auricle to ventricle, presented different appearances in the upper and lower parts, from which it appeared probable that the upper portion of the clot had existed some time previous to death, and that the lower was of post-mortem origin. The upper part had a clear amber-coloured, transparent appearance, and was traversed by delicate bands of fibrous tissue, entering it at its base, and continuous with the lining membrane of the auricle. Under the microscope this portion exhibited numerous nucleated cells, of various sizes and forms: many were elongated and spindle-shaped, pointed at both extremities, and dilated in the centre, the nuclei being round and oval; spherical cells were also very abundant. In addition to cells, there were numerous bands of filamentous or fibrous tissue, such as exist in ordinary areolar tissue. No vessels were detected. The lower part of the clot, from about the free border of the mitral valve, presented the ordinary appearances of coagulated fibrine, coated with a layer of red coagulum, generally found in the cavities of the heart at post-mortem exami. nations.

Nothing of importance was noticed in the other viscera, but the following appearances were observed in the arteries of the left leg:-The lower part of the popliteal artery, through two inches of its length, and the posterior tibial, for half an inch below the origin of the femoral, were filled with firm, contracted coagulum, which also extended a quarter of an inch into the orifices of the anterior tibial and perinæal arteries. At its upper and lower extremity, but to a greater extent at its upper, this clot was pale, and firmer than in other parts, presenting the ordinary appearance of contracted, decolorized fibrine; in its central portion it was less altered, being of a mottled blood-colour, and much softer. In all parts the clot was adherent to the lining membrane of the artery. The coats of the popliteal artery, from about the centre of the clot, and also the anterior and posterior tibial, and the peronæal, were studded with small osseous plates, and speckled with atheromatous matter; in the upper part of the popliteal, and in all parts of the femoral artery, were numerous patches of atheromatous matter.

Mr. Clark stated, in some clinical remarks, that it was to be regretted that a more accurate account of the patient's condition at the commencement of the attack conld not be obtained. The patient was unable to afford any further information himself, and he (Mr. Clark) could not learn anything from the locality where he lived. Mr. Clark's impression regarding the cause of the mortification was drawn from the existing condition of the limb rather than from the history, and was expressed shortly after his admission. He believed that there had been some disorganizing process in the main artery of the limb, by which the circulation had become obstructed by the deposition of a clot within it; and that the death of the extremity resulted from mechanical interference to the supply of arterial blood. The man's previous habits and deteriorated health were the cause of his death; had they been favourable, there was no reason why he should not have gone through the process of separation of the dead part, for the drain upon the system, and the constitutional disturbance dependent thereon, were by no means excessive.

The condition of the vessels of the limb verified his (Mr 
Clark's) prediction as to the cause of mortification; but the actual morbid condition of the artery, and the exciting cause of this condition, were by no means so clearly established, any opinion on these points must, therefore, be purely speculative. He imagined that cold, acting on an enfeebled frame, was the exciting cause of the mischief. Whether the actual condition was one of inflammation of the lining membrane of the vessel ho did not venture to conjecture. The term itself was too vague, and accepted with such various limitations by different writers, that it was dangerous to nse it without first defining the exact meaning or interpretation which should be attached to it. But he apprehended that in this instance there was some process established, destroying vitality, by which the mutual healthy relations between the interior of the artery and its contents were altered: by this he believed the vitality of both to have been impaired to such an extent, as to account for the spontaneous coagulation of the blood and its adhesion to the lining membrane of the vessel.

The adherent mass within the left auricle had been an object of careful examination, in which he had been assisted by Mr. Adams and Mr. Rainey. Its position was such as materially to interfere with the natural course of the blood. It was, first of all, Mr. Clark's impression, from a superficial observation, that the body in question was fibrinous, and possibly organized. But on careful examination under the microscope, an abundant areolar tissue was apparent, and the various-shaped nucleated cells mentioned in the autopsy were, in the opinion of Mr. Rainey, many of them resembling the ordinary epithelial cells of the lining membrane of the heart and arteries. Whatever might be the actual nature of the growth, it was very firmly, indeed inseparably, connected to the endocardium, and its clear, amber-coloured appearance certainly presented to the naked eye very much the aspect of fibrine.

\section{Gur's Hosfital. \\ Medullary Sarcoma of the Testicle.}

(Under the care of Mr. Cock.)

We had, a little time ago, (The LANCET, April 27, 1850, p.511, occasion to report two cases of disease of the testis, which had necessitated the removal of the organ. The first was of a scrofulous kind; of the second, there were some doubts as to its being a malignant affection. The tumour was, however, of a stony hardness; and if we do not err, scirrhus very rarely affects the testis.

The patient of Mr. Cock, a sketch of whose case we shall now attempt to give, was labouring under medullary sarcoma of the testicle, uncomplicated either by diseased lambar glands or ulceration of the scrotum. Here also castration was performed, and we venture to think, with great propriety; for as the disease may be strictly local, there is a chance of preventing the contamination of the system by an early removal. It must be confessed that the chance is but a very poor one, for examples of the return of the disease are overwhelmingly numerous; but as medicines are powerless, in such cases, it would be almost cruel to deprive the patient for an undetermined time of comparative comfort, merely because he may die of the same disease in another or the same organ. Indeed, we recently saw Mr. Wormald, at St. Bartholomew's Hospital, remove a large portion of the tongue of a patient, for cancerous disease of that organ ; and though the man may eventually die of cancer, as happened to the unfortunate Dr. Reid, of St. Andrew's, it is a real charity to postpone the evil day, and diminish the patient's sufferings, the surgeon of course apprizing his patient of the real state of the case. The following details, furnished by Mr. Madge, are of some importance, as they show a certain kind of filiation between former affections of the testicle, derangement of the genito-urinary apparatus, and eventual development of malignant disease.

The patient was a fisherman, about thirty-nine years of age, who had always enjoyed good health, though spinal disease and skin affections were prevalent among his family. He caught the venereal disease at twenty-five. The chancre, being of the phagedænic kind, proceeded to the destructive ulceration of the glans penis and prepuce, both of which parts were completely removed. A firm cicatrix was left at the point where the glans is in apposition with the corpora cavernosa. The meatus urinarius had always been very small and contracted, though generally no difficulty of emptying the bladder was experienced; but about two years ago the patient applied to Mr. Cock, with symptoms of stricture. These were soon removed by dilatation, and have not since reappeared. Soon after this the patient contracted gonorrhoea, and had, during the continuance of the disease, rather severe orchitis in the left testicle. He again placed himself under
Mr. Cock. The discharge, as well as the inflammation of the testis, were soon removed, and the patient was discharged, apparently quite well; yet about sixteen months ago, after a hard day's work, in carrying heavy loads on his back, he first perceived a swelling in the left testis. This was accompanied by pain, extending to the back and loins, and down the left thigh. This state of things, as far as the patient can recollect, did not result from any blow or violence offered to the testicle. The following morning the pain and swelling had nearly all sabsided, he went to his work as usual, and being now free from pain, he paid but little attention to the tumour, but thinks, however, that it must have gradually increased from the last-mentioned date. Last January, after severe exertion, very acute pain was again felt in the testicle, loins, back, \&c.; the swelling had reached a considerable size, and was noticed to be on the increase. The patient now took mercury, under the advice of a private practitioner; but though carried to salivation, this remedial action had no effect on the tumour; it continued to enlarge, without, however, giving pain or disturbing the general health; and the patient was admitted into the hospital on the 20th of February.

On examination the tumour was found to be about the size and shape of a turkey's egg, with the large end inferiorly; it felt hard and irregular, except at the lower part, where distinet fluctuation was detected; a trochar was introduced, and about half an ounce of straw-coloured clear fluid drawn off. At this period the cord appeared free from disease, and $\mathrm{Mr}$. Cock determined to try the effect of pressure upon the enlarged testis, as mercury had already been administered without success. The organ was therefore kept firmly strapped for about three weeks, but this measure proved unavailing. Malignant disease was now suspected; and though the patient had not the appearance and general symptoms characteristic of cancer, Mr. Cock proposed castration, being convinced that if removal is to be attempted at all, it should take place early.

On the 19th of March the patient was brought into the operating theatre, and having been rendered insensible by chloroform, Mr. Cock made an incision in the direction of the cord, about. two inches and a half in length, commencing a little above the external ring, and running obliquely downwards and inwards through the anterior part of the scrotum. By a careful division of tissues over the spermatic cord, the latter was exposed, and raised by passing a curved needle armed with a thread underneath it. The cord appeared to be in a healthy condition, and Mr. Cock divided it about three-quarters of an inch from the external ring. The tumour was then easily dissected out of the scrotum; and after securing the spermatic artery with some of its branches, and the artery accompanying the vas deferens, the upper edges of the wound were brought into close apposition by means of several sutures, and the lower, left partially separated to allow the escape of any discharge which might take place.

On making a section of the tumour, it was found to consist of a confused mass of disease; no healthy portion of testis could be recognised; the normal structures had probably been compressed by the medullary matter interstitially deposited, and were consequently atrophied. Mr. Birkett, on examining the diseased organ under the microscope, pronounced it genuine medullary sarcoma. The patient progressed very favourably for some time, and there was every reason to believe that he would make a speedy recovery; but he was unfortunately attacked by symptoms of phlebitis, under which affection he rapidly sank eleven days after the operation.

It should be noticed that a tendency to an inflammation of veins and consequent purulent deposits was prevalent in the hospital to a very serious extent. The most favourable cases were suddenly destroyed by this dreadful complaint; every surgeon of the establishment experienced similar losses, and it is rather strange that the disease did not reign in one or two wards in particular, but broke out at the same time upon distant points of the institution. The epidemic was likewise noticed in St. George's Hospital at the same period, and atmospheric influence was at one time thought to exercise some influence on this state of things; but this idea could not be supported, as varions other institutions were at the same time quite free from any epidemic Local causes must therefore have been mainly concerned in these phenomena.

On a post-mortem examination of Mr. Cock's patient, conducted by Dr. Lloyd, the external wound was found nearly healed, but the cavity of the scrotum, or sac of the testis, was sloughy, and the cord the seat of suppurative infiltration. The left spermatic vein was granular, and full of pus as far as its termination in the renal vein. The vena cava contained puralent matter, and in the pulmonary artery were found ante-mortem clots, suspected to contain pus-globules, which, however, were 